\title{
Identity Integration across Cultural Transitions: Bridging Individual and Societal Change
}

\author{
Moin Syed \\ University of Minnesota \\ Journal of Psychology in Africa \\ Special Issue: Identity in Transition: South Africa, Africa, and Beyond \\ Draft 3
}

This is a post-print version of:

Syed, M. (2017). Identity integration across cultural transitions: Bridging individual and societal change. Journal of Psychology in Africa, 27(2), 105-114.

Address correspondence to moin@umn.edu 


\begin{abstract}
Identity research has proliferated in recent years creating a great need for theoretical clarity about the identity concept, and how to use this clarity to understand identities within specific contexts. The present article addresses this need by discussing theoretical aspects of identity development as they apply to another important, yet broad, developmental context: societies in transition. This article includes a brief background on identity research in developmental psychology, an introduction of key theoretical constructs of identity integration, and then finally application of these constructs to understanding identities in transition. The hope is that this theoretical discussion will stimulate further research on identity development in the context of individual and social transitions.
\end{abstract}

Keywords: Identity, Immigration, Transitions, Development, Acculturation 


\section{Identity Integration across Cultural Transitions:}

\section{Bridging Individual and Societal Change}

Creating and maintaining a sense of identity is frequently hailed as the central developmental task of adolescence and emerging adulthood (Arnett, 2011; Erikson, 1968), and may perhaps be the central defining feature of a human life (Erikson, 1950; McAdams, 2013a). In accordance with these grand claims, identity is a concept that has been studied from the earliest days of psychology (James, 1890), has been represented throughout the social sciences, humanities, and the arts (Brubaker \& Cooper, 2000; Côtė, 2015; Syed, Azmitia, \& Cooper, 2011), including in cultural and cross-cultural studies (Cooper, Gonzalez, \& Wilson, 2015; Crocetti, Schwartz, Fermani, Klimstra, \& Meeus, 2012; Hammack, 2015).

Given this breadth of potential applications of identity there is a great need for theoretical clarity in identity research, and how to use this clarity to understand identities within specific contexts. The present article addresses this need by discussing theoretical aspects of identity development as they apply to another important, yet broad, developmental context: cultural transitions. As will be discussed in more detail, cultural transitions reflect periods of both temporary uncertainty and opportunity; something in life has changed. Such changes can pose both threats and assets to individuals' identities, issues that must be resolved to maintain a positive sense of self (see Cooper, 2011; Mpofu, Bakker, \& Levers, 2011; Sam \& Berry, 2010).

Pertinent questions include: How do identity threats and growth opportunities operate in the context of transitions? Why do transitions potentially serve as threats and assets to the developing self? These are the questions I will take up in the article. In doing 
so, my focus is largely theoretical and speculative, relying on empirical data when available, but not being handcuffed by its presence or absence. First I provide a brief background on identity research in developmental psychology, then I introduce key theoretical constructs of identity integration, and then finally I apply these constructs to understand some of the key issues young people face as they develop their identities during times of transition.

Importantly, the intent of this article is not to make value claims on what constitutes a "good" or "bad" identity, which unfortunately has been the case in some of the past work on identity using U.S.-based standards as the basis for judgements of quality (see Phinney \& Baldelomar, 2011, for a discussion). This tendency reflect the broader practice in developmental psychology, particularly research with children, which has often held knowledge gained from the White American middle-class samples as a standard by which others are evaluated (Nsamenang, 2012). The purpose of this article is to outline theoretical constructs related to identity integration that could potentially be applied in a variety of settings, including emerging countries. Following the lead of some cultural psychologists (e.g., Jensen, 2012; Shweder, 1999), although the processes of identity integration may be generalizable, the specific content of the identities and whether or not they are adaptive will very likely be dependent on the local context.

\section{Very Brief History and Review of Identity Research in Psychology}

To understand identity integration in the context of transitions, it is useful to have a sense for the general nature of research on identity in psychology, particularly developmental psychology. Despite the richness of the identity concept, the psychological approach to studying identity has been rather limited in scope (see also Côté, 2015; van Hoof, 1999). As I will detail below, the psychological approach to identity has clung to a few 
early models that examine a narrow set of processes. Psychological theory and research on identity falls into two very broad categories that align with social psychology and developmental psychology (Hammack, 2015). The social psychological approach is rooted in sociological concepts of the self in context, how expressions of identity are closely tied to the circumstances of situations, interactions, and self-other perceptions (Ashmore, Deaux, \& McLaughlin-Volpe, 2004). Much of the research on identity in social psychology comes from an intergroup relations perspective (Tajfel \& Turner, 1986). That it, the focus of analysis is how salience of identities is activated in settings composed of differing group membership, and the subsequent implications of that salience for behavior and attitudes (see Verkuyten, 2016, for a review). More recently, attention has been paid to multiple social identities, or how individuals view the connection or overlap among the different worlds they inhabit (Amiot, De la Sablonniere, Terry, \& Smith, 2007; Deaux \& Perkins, 2001; Hurtado, 2003; Roccas \& Brewer, 2002).

In contrast, the developmental approach to identity has its roots in Erik Erikson's $(1950,1968)$ lifespan theory of development. Whereas the social psychological approach emphasizes situational identities, Erikson conceptualized identity as a life-long developmental intra-psychic process-albeit one that occurs within social and cultural contexts (McLean \& Syed, 2015; Syed, 2012). For Erikson, identity was more about the sense of being across the past, present, and future, as opposed to the "here and now" of social identity. Being a clinician and field researcher, Erikson's writings cover vast territory that meanders through various concepts, pushing them in different directions to attempt to arrive at some fundamental understanding (Waterman, 2015). 
Although Erikson's style serves as rich fodder for thinking about the form and function of identity across the lifespan, from an empirical research perspective it poses many challenges. Erikson's theorizing is not easily amenable to the operational definitions desired by quantitative psychological researchers. In an attempt to convert Erikson's theory into something empirically manageable, Marcia $(1966,1980)$ asserted that the fundamental core of Erikson's theory is the process through which individuals arrive at a sense of identity. He further asserted that two underlying processes could provide insights into the route to which individuals have traveled to arrive at their identities: exploration, which is the degree to which individuals engage in evaluating a variety of identity alternatives, and commitment, which is the degree to which individuals adopt a particular identity and all that it entails. When taking these two process together, Marcia argued, one could gain insight into the current structure, or status, of individual identities: a history of past exploration paired with current commitments reflects achievement, current commitments with no past exploration is foreclosure, current exploration absent commitment is moratorium, and the absence of both exploration and commitment is diffusion. These four identity statuses represent something of a developmental continuum, in that there is generally expected to be a movement from diffusion and foreclosure through moratorium and to achievement (Kroger, Martinussen, \& Marcia, 2010; Waterman 1982).

The identity status model quickly caught on, generating a large body of research (for reviews see Kroger \& Marcia, 2011; Marcia, 1980; Meeus, 2011; Waterman, 1982). Marcia’s (1966) initial model focused on the identity domains of occupation and ideology, but the model was subsequently extended to include politics, religion, family and peer 
relationships, romantic relationships, gender roles, and ethnicity, among others (Archer, 1989; Grotevant, Thorbecke, \& Meyer, 1982; Phinney, 1990). The processes of exploration and commitment themselves have also been refined and expanded, with new models and greater prevalence of longitudinal studies resulting in stronger evidence for the developmental properties of the identity status model (Carlsson, Wängqvist, \& Frisén, 2015; Crocetti, Rubini, \& Meeus, 2008; Crocetti \& Meeus, 2015; Kunnen \& Metz, 2015; Luyckx, Goossens, \& Soenens, 2006; Meeus, 2011).

Despite this increase in the breadth of identity domains and processes examined, the modal approach to studying identity development is to assess exploration and commitment across a sampling of domains and then provide an overall, or global, identity status (Meeus, 2011). These identity statuses are then examined for a variety of differences in putative developmental antecedents and sequelae (see Martinussen \& Kroger, 2013; Meeus, 2011; Rivas-Drake, Seaton et al., 2014; Rivas-Drake, Syed et al., 2014; Schwartz, Zamboanga, Luyckx, Meca, \& Ritchie, 2013). This is more or less the nature of the identity developmental literature, until recently.

In the last decade or so there has been resurgent interest in Erikson's original ideas about identity development, to embrace some of the richness that is absent from the identity status model (see Syed, 2012). As noted previously, Erikson wrote a great deal on the topic, and his writings serve as voluminous source material for contemporary empirical researchers to investigate identity development. This movement has led to a reintroduction of many Eriksonian concepts that had been forgotten, never understood, or not fully appreciated, such as the idea of identity configurations (Hammack, Thompson, \& Pilecki, 2009; Schachter, 2004, 2005; Syed, 2010), the distinction between ego, personal, 
and social identity (McLean, Syed, Yoder, \& Greenhoot, 2016), and the role of the broader societal and cultural context (Way \& Rogers, 2015).

A major theme of Erikson's theory of identity development, which has always been recognized, is that of integration. Identity integration broadly pertains to individuals developing a sense that all parts of who they are-past, present, and future-fit together in some meaningful way in order to structure and guide their lives. A sense of identity integration represents optimal psychological functioning and is therefore the ideal identity state as individuals develop from adolescence through adulthood. Nevertheless, individual experience threats to identity integration throughout the lifespan, and thus identity is never fully settled or resolved. Rather, a reasonably integrated identity is one that is able to easily assimilate challenge (i.e., deal with the challenge using minimal resources) or successfully accommodate it (i.e., make larger changes to the identity structure).

As noted, identity development researchers have always recognized the centrality of identity integration, but it has scantly been investigated directly or faithfully. Moreover, there are several different types of integration that appear in Erikson's theory that need to be separated (and hopefully put back together) through empirical study. The interested reader is encouraged to consult Syed and McLean (2016) for an in-depth treatment of this issue, but I provide a brief review below before discussing implications for these theoretical ideas for studying identities in transition.

\section{Forms of Identity Integration}

Syed and McLean (2016) recently identified four different types of Eriksonian identity integration: contextual, temporal, ego, and person-society (Figure 1). We do not assert that these are a complete and universal set, but rather our current interpretation of 
Erikson's theory. Understanding these four different types of identity integration serves two clear purposes. First, disentangling the types and isolating them allows interested readers to take a more in depth examination of that type. For example, in Syed and Mitchell (2015) we focused exclusively on literature pertaining to temporal integration, attempting to unite the ways in which different psychological sub-fields address this important development process. The review highlighted that, although a good deal of research focuses on how individuals experience and make sense of their past, present, or future, very few studies actually incorporate assessments of all three temporal components. Thus, a full analysis of temporal identity integration is generally lacking in the field. These kinds of indepth examinations can serve to generate new lines of empirical research and encourage continued theorizing. Second, having a better understanding of the different forms of integration is useful for interpreting and mapping the extant literature, identifying areas for which a cumulative knowledge may be developing (e.g., in the case of contextual integration) as well as areas where surprisingly little is known (e.g., ego integration). Similarly, the knowledge helps to situate past studies appropriately vis-à-vis a new focal study, contributing to a more theoretically sound conceptualization. I now briefly introduce each of the four forms of integration.

Contextual integration. Contextual integration is perhaps the most widely studied of the four types. It refers to the integration and synthesis of the different life spaces, or domains, individuals inhabit. All individuals have multiple identity domains that they navigate. These domains are varied, and can include gender, ethnicity, occupation, religion, family, and so on. The domains that are important are dependent on what is salient to the individual. In other words, each individual has a fluid set of identity domains with which 
they must reckon. This reckoning takes the form of developing a sense of integration and coherence among these domains, a sense that the domains fit together, or at least are not in conflict. Within the identity literature contextual integration is primarily studied in terms of "multiple identities" (Gonzales-Backen et al., 2015; Kiang, Yip, \& Fuligni, 2008; Meca et al., 2015). As discussed in Syed and McLean (2016), however, these studies are not faithful to the concept of contextual integration because they do not actually assess the degree to which multiple identities interact with one another, rather they document the existence of configurations of different domains within individuals. A useful endeavor, to be sure, but the studies do not actually capture contextual identity integration.

Temporal integration. While contextual integration pertains to within-time integration of identity domains, temporal integration pertains to the self through time, focusing on how individuals integrate their past experiences, current pursuits, and future endeavors. Temporal integration provides a sense of personal continuity, such that individuals can derive feelings of consistency and stability of the self across the lifespan. The successful integration of the past and present, in particular, facilitates a movement towards the future, as it permits an extension of the self across the spectrum of time. Temporal integration has been studied in variety of ways (see Syed \& Mitchell, 2015), but most directly by researchers adopting the narrative model of identity. Narrative identity is focused on the processes of how and why people tell stories about the past. The key mechanism from this perspective is autobiographical reasoning, defined as the process through which people connect past experiences to their current sense of self (Habermas \& Köber, 2015; McAdams \& McLean, 2013). A robust literature on narrative identity has been 
developing over the years, deepening our understanding of temporal integration (see Adler, Lodi-Smith, Philippe, \& Houle, 2016).

Ego integration. Ego integration represents a non-additive synthesis of the previous two forms of integration, contextual and temporal. It is non-additive in that it is not simply contextual plus temporal. Rather, ego integration involves the evolving and dynamic process of coordinating multiple identities domains across time. In this way, it arguably is the "truest" sense of identity integration from an Eriksonian perspective. Ego integration involves the sense of identity that Erikson wrote about, and involves both unconscious identity work and conscious reflection of one's past life in order to arrive at a meaningful, coherent, present. Assessing this type of integration is rare in the empirical literature, and likely requires longitudinal case-based analyses to do so (e.g., Josselson, 2009; Syed, 2010).

Person-society integration. The fourth and final type of identity integration, person-society integration, pertains to how individuals integrate with the broader society. Erikson discussed this concept primarily in terms of social identity, or how individuals express and understand their selves within a social world, contoured by social structures. An important contemporary approach to this type of integration is examining how individuals engage with stereotypes about their group memberships (Way \& Rogers, 2015) and how identities are affected by internalized racism (Ajayi \& Syed, 2016). These examples illustrate how aspects of society and social structures become part and parcel with peoples' identities.

In sum, identity integration is multidimensional, and when taking the four forms together, covers a great deal of ground. As noted, a major goal of this article is to apply 
these concepts to identities in transition, but first a brief discussion of transitions is in order.

\section{What are Transitions?}

Transitions have a long history of being centrally important in developmental psychology, both conceptually and empirically (Seidman, Allen, Aber, Mitchell, \& Feinman, 1994; Suárez-Orozco, Abo-Zena, \& Marks, 2015). Indeed, some have argued that is essentially what development is, a series of adaptations to transitions small and large (Hendry \& Kloep, 2007; Piaget, 1952). Generally speaking, the empirical focus on transitions has primarily examined schools transitions, i.e., the transition from primary school to secondary school (Wigfield, Eccles, Mac Iver, Reuman, \& Midgley, 1991) or secondary school to higher education (Azmitia, Syed, \& Radmacher, 2013), or life transitions such as becoming a parent (Kerrick \& Henry, 2016), divorce (Cookston \& Remy, 2015), job loss (Shepherd \& Williams, 2016), or death of loved one (Parkes, 1988).

Receiving relatively less attention in developmental psychology, but more from other fields, are cultural transitions. Cultural transitions often involve individuals shifting their life space from one cultural context to a different cultural context, most typically in terms of relocating from one nation to another. We can call these migratory transitions. It is important to note that the types of transitions mentioned previously-school, parenthood, etc.-are most certainly "cultural" in nature. These are best conceptualized as culturespecific transitions, as their occurrence and meaning is bound up with the cultural ideals and practices in which they occur. In contrast, cultural transitions are concerned with the transitions between cultures in which individuals live. Cultural transitions have been extensively studied with respect to the psychological process by which individuals adapt to 
new cultures (Szabo, Ward \& Fletcher, 2016). This research represents an individual level of analysis, with an extreme-and often exclusive-focus on how individuals navigate a cultural transition exerting influence on their lives. But there are two others types of cultural transition that must also be considered vis-à-vis identity development.

First, as many scholars have argued (Hurtado, 2003; McLean \& Syed, 2015) cultural adaptation cannot be thought of in uni-directional terms. That is, culture does not only have a top-down effect on individuals inhabiting them, but there is also a bottom-up effect of individuals on the cultures themselves (Gjerde, 2004). The accumulation of individuals making cultural transitions and adaptions ultimately results in the cultures adapting to them as well. Thus, cultural adaption through transition is very much a bi-directional process in which both individuals and cultures adapt.

Conceptualizing transitions in this way brings attention to the second, broader type of cultural transition: cultural transitions for those who are not making a transition but rather are subject to a transition. We can call these stationary transitions. If we accept the idea that cultures change in response to those who are a part of them, then it stands to reason that individuals with a history of living in a particular cultural context will need to adapt to such changes. Some changes can be slow whereas others can be quite fast. Nevertheless, these changes create the need for new types of identity work that has been scantly studied. The distinction between migratory and stationary transitions harks Ogbu and Simon's (1988) distinction between voluntary and involuntary immigrants. Voluntary immigrants are those who made the transition of their own will, seeking to change contexts to "seek a better life" or have access to new opportunities in some way. In contrast, involuntary immigrants had no such choice. They might have been forced to leave their 
homeland due to political conflict such as the case of refugees, taken from their homeland such as the case of slaves from Africa, or due to power grabs via colonization, rendering the indigenous peoples as the "minorities," such as the case of Native Americans, Blacks in South Africa, and so on. The important point here is that "cultural transitions" are complex and multifaceted, and these types of issues should be considered when aiming to study identities in transition (see also Bierwiaczonek \& Waldzus, 2016). With these three forms of cultural transition in mind, I now turn to a discussion of identity integration in the context of cultural transitions.

\section{Identity Integration during Cultural Transitions}

In this section, I highlight key issue and questions that arise when thinking about identity integration in the context of cultural transition, with the ultimate goals of motivating future research and theorizing. Below I discuss, in turn, how each of the four forms of integration is applicable to cultural transitions.

Contextual integration. Contextual integration has perhaps received the most empirical attention with respect to cultural transitions, although it has not often been framed in these terms. The metaphor of being "between two worlds" has become standard for representing how immigrants and sojourners manage potentially competing cultural demands (Das \& Kemp, 1997; Ngo, 2008; Gyberg, Syed, Frisén, Wängqvist, \& Svensson, in press). Indeed, the dominant "acculturation strategies" model (Berry, Phinney, Sam, \& Vedder, 2006; Sam \& Berry, 2010) specifies that individuals from immigrant backgrounds must navigate the attitudes, beliefs, values, and behaviors of two cultures. From this perspective, the optimal strategy is one of integration or biculturalism, wherein individuals are able to maintain aspects of both their heritage and host culture (Berry, 1980). Although 
there have been many questions about the adaptiveness of biculturalism (Rudmin, 2009), meta-analyses suggest that it is associated with more adaptive outcomes than other strategies (Nguyen \& Benet-Martinez, 2013; Yoon et al., 2013). Thus, from this perspective, cultural transitions can provide opportunities for developing a positive sense of self within multicultural societies.

This bicultural perspective stands in stark contrast to the previously prevailing view that cultural orientation was unidimensional, in that as individuals oriented more towards one culture they necessarily oriented less towards the other (Berry, 1980). But rather than be prescriptive of what ought to be, or even descriptive of what is the case, the acculturation strategies model allows for individual differences in how people structure their lives. Thus, the unidimensional perspective may be (and is) adopted by some individuals, represented by both the assimilation (oriented towards host culture while distancing from heritage culture) and separation (distancing from host culture while maintain heritage culture) strategies.

The acculturation model has been recently pushed even further, most notably through Ferguson's (Ferguson \& Adams, 2016; Ferguson \& Bornstein, 2012) tridimensional model. This model of acculturation raises important issues about how cultural identities are influenced and structured in contemporary society. Ferguson has introduced the concept of remote acculturation as a way of understanding how cultures in which individuals do not actually participate can still have an influence on their identities. Studies conducted in Jamaica and South Africa (Ferguson \& Adams, 2016; Ferguson \& Bornstein, 2012) have demonstrated that, in addition to host and heritage cultures (or mainstream and minority cultures), individuals living in these nations also orient towards American 
culture. Globalization, codification, and exportation of American culture have resulted in a cultural orientation that is easily accessible and, in many ways, must be reckoned with, even absent direct contact.

While the acculturation strategies model-and the tri-dimensional extensioncertainly capture contextual identity integration, they are also limited in how they do so. Much of the research tends to focus on very broad notions of cultural orientation, even when examining the different dimensions of values, beliefs, and behaviors. Moreover, contextual integration only captures a snapshot in individuals' development, a moment in time.

Temporal integration. Acculturation models tend to focus on the strategies people adopt following arrival in their new countries, how people structure their lives after the transition. The same can be said for research on international student/sojourner adjustment (Hirai, Frazier, \& Syed, 2015). What has received less attention is how individuals manage their lives across the transition itself. A greater focus on temporal integration would facilitate such inquiries.

With its focus on how individuals find personal continuity across the past, present, and future, temporal integration is an ideal theoretical concept to apply to experiences of immigration, in particular. For instance, moving across national borders can serve as a majorly disrupting event, especially when the two nations have few cultural similarities. Even if they do, there will always be a sense of "left behind" associated with the old culture and a sense of "newness" with the culture. This being a case of fact, the psychological work involved with the transition is not to shed these associative senses but rather to mend them. That is, the developmental task associated with migratory transitions is one of 
reconciliation of past and present in order to ensure a successful future-how people thrive in the face of transition.

Unfortunately, there have been few empirical studies adopting this approach. Part of the problem is the lack of longitudinal studies in this literature in general, but even the available longitudinal studies tend to only include measurements post-arrival rather than following participants across the transition. There are, of course, barriers to conducting such studies, as researchers must be able to identify individuals on the precipice of a transition. Although longitudinal studies are-and should be-the gold standard for understanding temporal continuity, they are by no means the only useful method. I provide an example below.

The study of temporal continuity within the identity literature has largely been studied from a narrative perspective (Syed \& Mitchell, 2015). One of the central developmental mechanisms within the narrative psychological approach to identity is autobiographical reasoning (Habermas \& Köber, 2015). Autobiographical reasoning refers to a broad family of more specific social cognitive processes that all pertain to how individuals make sense of their past experiences and how they are connected to the self (McAdams \& McLean, 2013). Thus, from this perspective longitudinal studies are desirable but not required, as the focus is on how individuals at the present moment make sense of their past experiences. The "present moment" qualifier in the preceding is critical, as autobiographical reasoning about the "same" past event can itself change over time (Josselson, 2009; McAdams et al., 2006; Syed, 2010; Syed \& Azmitia, 2010; Thorne, Cutting \& Skaw, 1998). Accordingly, cross-sectional studies in which individuals are prompted to 
narrate their migration experience can be quite useful for understanding temporal continuity at a given moment.

Benish-Weisman (2009) conducted just such a study, using in-depth interviews with adult immigrants from the former Soviet Union living in Israel. The analysis focused primarily on two features of the narrative: the structure of the story told and the degree of coherence evidenced in the narrative. While coherence is an important concept within narrative psychology (McAdams, 2006; Fiese \& Spagnola, 2005; Waters \& Fivush, 2015), here I want to highlight the structural analysis. The structural analysis involved identifying the narratives as progressive (generally moving forward), regressive (general decline) or stable, and then detailing the specific form of the story within. Progressive stories tended to take on a romance form, in which there were many ups and downs en route to a happy ending (i.e., current state). The romance story is a form of redemptive story in which individuals narrated negative experiences as leading to positive outcomes (Dunlop \& Tracy, 2013; Hammack, 2006; McAdams, 2013b). One of the most intriguing regressive story types identified was the fracture story. Fracture narratives included two distinct components, a pre-migration self and a post-migration self, with no expressed ability to connect the two. In this way, "immigration functions as a splitting point in the story" (Benish-Weisman, 2009, p. 962).

This type of analysis raises some critical issues for future research to examine (see also Catalano, Fox, \& Vandeyar, 2016). Importantly, these issues go beyond the migratory context. How do transitions create ruptures to continuity? What are the specific types of experiences or contexts that can create ruptures? How do individuals mend those ruptures? Why are some people able to construct romance stories while others construct 
fracture stories? Why are cultural transitions threats to healthy identity for some people, whereas they serve as opportunities for growth for others? Does the difference have to do with individual differences or contextual factors? Or both? As yet, we know few-if anyanswers to these questions.

Ego Integration. As previously mentioned, there are few studies of ego integration, in relation to transitions or otherwise. However, there are clear applications, notably in terms of how the nature of salient identity issues can change across cultural transitions. Particularly in the context of migratory transitions, the set of identity issues that individuals must negotiate pre-transition and post-transition can be distinct, and this difference might need to be reconciled. For now, all we can really say is there needs to be more empirical research on this form of integration to begin to understand it properly.

Person-society integration. Person-society integration has not been a particularly frequent focus of psychologists studying identity. It has, however, been examined more closely in other domains that are related to identity, such as research in the Vygotskian (1978) tradition of examining culture as a community of practice (Nsamenang, 2012; Rogoff, 2003). For example, Serpell (2007) described the need for adapting the Western higher education model for the African context(s), incorporating indigenous concepts such as instruction that is contextualized in real world practices and a focus on social responsibility. Similarly, Esteban-Guitart and Moll (2014) advanced the concept of "funds of identity" to draw attention to how individuals draw upon their culturally-specific, socially distributed resources to develop a positive, functional identity.

While valuable and useful, the research in the Vygotskian tradition tends to focus on situated contexts, or identities in the moment, rather than the broader ontogenetic identity 
processes that are captured by person-society identity integration. We recently argued that this type of identity integration is best understood through a master narrative framework (McLean \& Syed, 2015). Master narratives are culturally-available scripts that guide thoughts, feelings, and action. They correspond to what is good and valued within a cultural context, providing the template for how members of the society ought to be. In terms of identity integration, most individuals unconsciously align with the master narratives, as again, they dictate what is normative and acceptable within mainstream society (Hammack, 2008). But some people do not align with the master narratives, because they are not expected to by others or because they choose not. Such individuals work to develop alternative narratives, templates for experiences that go against the dominant, master narrative.

The master narrative framework and person-society integration have clear applications to studying identities in transition. In the context of migratory transitions, a necessary part of the adaptation is getting a handle on what the master narratives are in the new country, as they can vary considerably around the world (Hammack, 2008).

There are many potential threats to person-society integration largely stemming from the fact that individuals well-aligned with the master narrative in their home culture may suddenly find themselves not well-aligned in the new culture. Even in the case of relative ease of alignment, a society's master narrative about immigrants and how they should adapt may pose challenges. Cultures vary in their attitudes and beliefs about how immigrants ought to behave, with some countries like the U.S. espousing assimilationist views wherein immigrants are expected to shed ties with their heritage cultures in order to be fully American, whereas other countries such as Sweden expressly state that immigrants 
should maintain their heritage culture, and provide resources for them to do so (FerrerWreder, Trost, Lorente, \& Mansoory, 2012).

Finally, a master narrative perspective is applicable to stationary transitions. In fact, a society facing a cultural transition can be conceptualized as being in the midst of shifting master narratives. Indeed, while master narratives are certainly rigid, they are not set in stone. Major historical events can accelerate societal changes if they have the ability to alter the power structure. Examples can be seen in the context of racial oppression with the official abolishment of slavery and segregation in the U.S. and of apartheid in South Africa. While by no means overnight fixes to generations of violent oppression, they are historical events that have encouraged slow, but meaningful, changes in the existing power structure (Fuller-Rowell, Burrow, \& Ong, 2011; Long, 2016).

\section{Conclusion}

The purpose of this article was to describe how one theoretical concept, identity integration, could be applied to one developmental context, cultural transitions. The intent was largely to show how these two areas of research could be fruitfully integrated, to hopefully inspire future research and theorizing. There is, unfortunately, much more of theory than data at this point. These are important issues that cut to the core of the deeply psychological processes involved in developing identities, so I sincerely hope to see much more empirical research on the subject in the years to come. An important set of questions to ask pertains to the challenges to integration. What barriers to individuals encounter as they seek to lead healthy, productive lives? How do life contexts and experiences such as work, family, friends, material goods (hair/clothing,) spiritual practice, racialization, language, and so on potentially threaten the different form of identity integration? At the 
same time, we must also ask questions about opportunities and benefits of transitions. How do transitions lead to identity development and personal growth? What new opportunities are available to people as a result of the transition? How might transition differentially facilitate the various forms of identity integration? It is safe to say that researchers can stay busy addressing these questions for quite some time. 


\section{References}

Adler, J. M., Lodi-Smith, J., Philippe, F. L., \& Houle, I. (2016). The incremental validity of narrative identity in predicting well-being: A review of the field and recommendations for the future. Personality and Social Psychology Review, 20(2), 142-175.

Ajayi, A. A., \& Syed, M. (2016). How stigma gets under the skin: Internalized oppression and dual minority stress among black sexual minorities. In J. M. Sullivan and W. E. Cross (Eds.), Meaning-making, internalized racism, and African American identity. State University of New York Press.

Amiot, C. E., De la Sablonniere, R., Terry, D. J., \& Smith, J. R. (2007). Integration of social identities in the self: Toward a cognitive-developmental model. Personality and Social Psychology Review, 11(4), 364-388.

Archer, S. L. (1989). Gender differences in identity development: Issues of process, domain and timing. Journal of Adolescence, 12(2), 117-138.

Arnett, J. J. (2011). Emerging adulthood(s): The cultural psychology of a new life stage. In L. A. Jensen (Ed.), Bridging cultural and developmental psychology: New syntheses in theory, research, and policy (pp. 255-275). New York: Oxford University Press.

Ashmore, R. D., Deaux, K., \& McLaughlin-Volpe, T. (2004). An organizing framework for collective identity: Articulation and significance of multidimensionality. Psychological Bulletin, 130(1), 80-114.

Azmitia, M., Syed, M., \& Radmacher, K. A. (2013). Finding your niche: Identity and emotional support in emerging adults' adjustment to the transition to college. Journal of Research on Adolescence, 23(4), 744-761. 
Benish-Weisman, M. (2009). Between trauma and redemption: Story form differences in immigrant narratives of successful and nonsuccessful immigration. Journal of CrossCultural Psychology, 40(6), 953-968.

Berry, J. W. (1980). Acculturation as varieties of adaptation. In A.M. Padilla (Ed.), Acculturation: Theory, models and some new findings (9-25). Boulder, CO: Westview.

Berry, J. W., Phinney, J. S., Sam, D. L., \& Vedder, P. (2006). Immigrant youth: Acculturation, identity, and adaptation. Applied Psychology, 55(3), 303-332.

Bierwiaczonek, K., \& Waldzus, S. (2016). Socio-cultural factors as antecedents of crosscultural adaptation in expatriates, international students, and migrants. A review. Journal of Cross-Cultural Psychology, 47(6), 767-817.

Brubaker, R., \& Cooper, F. (2000). Beyond “identity.” Theory and Society, 29(1), 1-47.

Carlsson, J., Wängqvist, M., \& Frisén, A. (2015). Identity development in the late twenties: A never ending story. Developmental Psychology, 51(3), 334.

Catalano, T., Fox, J., \& Vandeyar, S. (2016). Being "in a limbo": Perceptions of immigration, identity and adaptation of immigrant students in South Africa and the United States. Journal of Language, Identity \& Education, 15(3), 137-150.

Cookston, J. T., \& Remy, L. (2015). Who am I if we're not us? Divorce and identity across the lifespan. In K. C. McLean \& M. Syed (Eds.), The Oxford handbook of identity development. New York: Oxford University Press.

Côté, J. (2015). Identity-formation research from a critical perspective: Is a social science developing? In K. C. McLean \& M. Syed (Eds.), The Oxford handbook of identity development. New York: Oxford University Press. 
Cooper, C. R. (2011). Bridging multiple worlds: Cultures, identities, and pathways to college. New York: Oxford University Press.

Cooper, C. R., Gonzalez, E., \& Wilson, A. R. (2015). Identities, cultures, and schooling: How students navigate racial-ethnic, indigenous, immigrant, social class, and gender identities on their pathways through school. In K. C. McLean and M. Syed (Eds.), The Oxford Handbook of Identity Development (pp. 299-318). New York: Oxford University Press.

Crocetti, E., \& Meeus, W. (2015). The identity status: Strengths of a person-centered approach. In K.C. McLean \& M. Syed (Eds.), The Oxford handbook of identity development (pp. 97-114). New York: Oxford University Press.

Crocetti, E., Rubini, M., \& Meeus, W. (2008). Capturing the dynamics of identity formation in various ethnic groups: Development and validation of a three-dimensional model. Journal of Adolescence, 31(2), 207-222.

Crocetti, E., Schwartz, S. J., Fermani, A., Klimstra, T., \& Meeus, W. (2012). A cross-national study of identity status in Dutch and Italian adolescents. European Psychologist, 17, $171-181$.

Das, A. K., \& Kemp, S. F. (1997). Between two worlds: Counseling South Asian Americans. Journal of Multicultural Counseling and Development,25(1), 23-33.

Deaux, K., \& Perkins, T. S. (2001). The kaleidoscopic self. In C. Sedikides \& M. B. Brewer (Eds.), Individual self, relational self, collective self. Philadelphia: Psychology Press.

Dunlop, W. L., \& Tracy, J. L. (2013). Sobering stories: Narratives of self-redemption predict behavioral change and improved health among recovering alcoholics. Journal of Personality and Social Psychology, 104(3), 576. 
Erikson, E. H. (1950). Childhood and society. New York: W W Norton \& Co.

Erikson, E. (1968). Identity, Youth and Crisis. New York, NY: W W Norton \& Co.

Esteban-Guitart, M., \& Moll, L. C. (2014). Funds of identity: A new concept based on the funds of knowledge approach. Culture \& Psychology, 20(1), 31-48.

Ferguson, G. M., \& Adams, B. G. (2016). Americanization in the Rainbow Nation remote acculturation and psychological well-being of South African emerging adults. Emerging Adulthood, 4(2), 104-118.

Ferguson, G. M., \& Bornstein, M. H. (2012). Remote acculturation: The “Americanization” of Jamaican islanders. International Journal of Behavioral Development, 36(3), 167-177.

Ferrer-Wreder, L., Trost, K., Lorente, C. C., \& Mansoory, S. (2012). Personal and ethnic identity in Swedish adolescents and emerging adults. New Directions for Child and Adolescent Development, 2012(138), 61-86.

Fiese, B. H., \& Spagnola, M. (2005). Narratives in and about families: an examination of coding schemes and a guide for family researchers. Journal of Family Psychology, 19(1), 51.

Fuller-Rowell, T. E., Burrow, A. L., \& Ong, A. D. (2011). Changes in racial identity among African American college students following the election of Barack Obama. Developmental Psychology, 47(6), 1608.

Gjerde, P. (2004). Culture, power and experience: Toward a person-centered cultural psychology. Human Development, 47, 138-147.

Gonzales-Backen, M. A., Dumka, L. E., Millsap, R. E., Yoo, H. C., Schwartz, S. J., Zamboanga, B. L., ... \& Brown, E. J. (2015). The role of social and personal identities in self-esteem among ethnic minority college students. Identity, 15(3), 202-220. 
Grotevant, H. D., Thorbecke, W., \& Meyer, M. L. (1982). An extension of Marcia's identity status interview into the interpersonal domain. Journal of Youth and Adolescence, 11(1), 33-47.

Gyberg, F., Syed, M., Frisén, A., Wängqvist, M. \& Svensson, Y. (in press). “Another kind of Swede": Ethnic identity in contemporary Sweden. Emerging Adulthood.

Habermas, T., \& Köber, C. (2015). Autobiographical reasoning in life narratives buffers the effect of biographical disruptions on the sense of self-continuity. Memory, 23, 564574.

Hammack, P. L. (2006). Identity, conflict, and coexistence: Life stories of Israeli and Palestinian adolescents. Journal of Adolescent Research, 21(4), 323-369.

Hammack, P. L. (2008). Narrative and the cultural psychology of identity. Personality and Social Psychology Review, 12(3), 222-247.

Hammack, P. L. (2015). Theoretical foundations of identity. In K. C. McLean \& M. Syed (Eds.), The Oxford handbook of identity development. New York: Oxford University Press.

Hammack, P. L., Thompson, E. M., \& Pilecki, A. (2009). Configurations of identity among sexual minority youth: Context, desire, and narrative. Journal of Youth and Adolescence, 38(7), 867-883.

Hendry, L. B., \& Kloep, M. (2007). Conceptualizing emerging adulthood: Inspecting the emperor's new clothes? Child Development Perspectives,1(2), 74-79.

Hirai, R., Frazier, P. F., \& Syed, M. (2015). Psychological and sociocultural adjustment of international students: Trajectories and predictors. Journal of Counseling Psychology, $62(3), 438-452$. 
Hurtado, A. (2003). Voicing Chicana feminisms young women speak out on sexuality and identity. New York: NYU Press.

James, W. (1890). The principles of psychology. New York: Holt.

Jensen, L. A. (2012). Bridging universal and cultural perspectives: A vision for developmental psychology in a global world. Child Development Perspectives, 6(1), 98-104.

Josselson, R. (2009). The present of the past: Dialogues with memory over time. Journal of Personality, 77(3), 647-668.

Kerrick, M. R., \& Henry, R. L. (2016). "Totally in love": Evidence of a master narrative for how new mothers should feel about their babies. Sex Roles, 1-16.

Kiang, L., Yip, T., \& Fuligni, A. J. (2008). Multiple social identities and adjustment in young adults from ethnically diverse backgrounds. Journal of Research on Adolescence, 18(4), 643-670.

Kroger, J., \& Marcia, J. E. (2011). The identity statuses: Origins, meanings, and interpretations. In S. J. Schwartz, K. Luyckx \& V. L. Vignoles (Eds.), Handbook of identity theory and research (pp. 31-53). New York: Springer.

Kroger, J., Martinussen, M., \& Marcia, J. E. (2010). Identity status change during adolescence and young adulthood: A meta-analysis. Journal of Adolescence, 33(5), 683-698.

Kunnen, E. S., \& Metz, M. (2015). Commitment and exploration: The need for a developmental approach. In K. C. McLean \& M. Syed (Eds.), The Oxford handbook of identity development (pp. 115-131). New York: Oxford University Press.

Long, W. (2016). Psychology in South Africa and the end of history. History of Psychology, 19(3), 220. 
Luyckx, K., Goossens, L., \& Soenens, B. (2006). A developmental contextual perspective on identity construction in emerging adulthood: change dynamics in commitment formation and commitment evaluation. Developmental Psychology, 42(2), 366.

Marcia, J. E. (1966). Development and validation of ego identity status. Journal of Personality and Social Psychology, 3, 551-558.

Marcia, J. E. (1980). Identity in adolescence. In J. Adelson (Ed.), Handbook of adolescent psychology, (pp. 159-197). New York: Wiley.

Martinussen, M., \& Kroger , J. (Eds.) (2013). Special Issue: Meta-analytic studies of identity status and personality. Identity: An International Journal of Theory and Research, $13(3)$.

McAdams, D. P. (2006). The problem of narrative coherence. Journal of Constructivist Psychology, 19(2), 109-125.

McAdams, D. P. (2013a). The psychological self as actor, agent, and author. Perspectives on Psychological Science, 8(3), 272-295.

McAdams, D. P. (2013b). The redemptive self: Stories Americans live by (Revised and Expanded Edition.). New York: Oxford University Press.

McAdams, D. P., \& McLean, K. C. (2013). Narrative identity. Current Directions in Psychological Science, 22, 233-238.

McAdams, D. P., Bauer, J. J., Sakaeda, A. R., Anyidoho, N. A., Machado, M. A., \& Magrino-Failla, K. et al. (2006). Continuity and change in the life story: A longitudinal study of autobiographical memories in emerging adulthood. Journal of Personality, 74(5), 1371-1400. 
McLean, K. C., \& Syed., M. (2015). Personal, master, and alternative narratives: An integrative framework for understanding identity development in context. Human Development, 58, 318-349.

McLean, K. C., Syed, M., Yoder, A., \& Greenhoot, A. (2016). The role of domain content in understanding identity development processes. Journal of Research on Adolescence, $26(1), 60-75$.

Meca, A., Ritchie, R. A., Beyers, W., Schwartz, S. J., Picariello, S., Zamboanga, B. L., ... \& Crocetti, E. (2015). Identity centrality and psychosocial functioning: A personcentered approach. Emerging Adulthood, 3(5), 327-339.

Meeus, W. (2011). The study of adolescent identity formation 2000-2010: A review of longitudinal research. Journal of Research on Adolescence, 21, 75-94.

Mpofu, E., Bakker, T., \& Levers, L. L. (2011). Counseling in African cultural heritage settings: The challenges and opportunities. In E. Mpofu (Ed.), Counseling people of African ancestry (pp. 313-316). New York: Cambridge University Press.

Ngo, B. (2008). Beyond "culture clash" understandings of immigrant experiences. Theory into Practice, 47(1), 4-11.

Nguyen, A. M. D., \& Benet-Martínez, V. (2013). Biculturalism and adjustment: A metaanalysis. Journal of Cross-Cultural Psychology, 44(1), 122-159.

Nsamenang, A. B. (2012). On researching the agency of Africa's young citizens: Issues, challenges and prospects for identity development. In D. T. Slaughter-Defoe (Ed.), Racial stereotyping and child development, 25 (pp. 90-104). Basel, Switzerland: Karger Publishers. 
Ogbu, J. U., \& Simons, H. D. (1998). Voluntary and involuntary minorities: a culturalecological theory of school performance with some implications for education. Anthropology \& Education Quarterly, 29(2), 155-188.

Parkes, C. M. (1988). Bereavement as a psychosocial transition: Processes of adaptation to change. Journal of Social Issues, 44(3), 53-65.

Phinney, J. S. (1990). Ethnic identity in adolescents and adults: A review of research. Psychological Bulletin, 108, 499-514.

Phinney, J. S., \& Baldelomar, O. A. (2011). Identity development in multiple cultural contexts. In L. A. Jensen (Ed.), Bridging cultural and developmental approaches to psychology: New syntheses in theory, research and policy, (pp. 161-186). New York: Oxford University Press.

Piaget, J. (1952). The origins of intelligence in children (Vol. 8, No. 5, pp. 18-1952). New York: International Universities Press.

Rivas-Drake, D., Seaton, E., Markstrom, C., Schwartz, S. J., Umaña-Taylor, A. J., French, S., Syed, M., Yip, T., Lee, R. M., \& Ethnic/Racial Identity Study Group. (2014). Ethnic and racial identity in childhood and adolescence: Implications for psychosocial, academic and health outcomes. Child Development, 85(1), 40-57.

Rivas-Drake, D., Syed, M., Umaña-Taylor, A. J., Markstrom, C., French, S., Schwartz, S. J., Lee, R. M., \& Ethnic/Racial Identity Study Group. (2014). Feeling good, happy, and proud: A meta-analysis of positive ethnic-racial affect and adjustment. Child Development, 85(1), 77-102.

Roccas, S., \& Brewer, M. B. (2002). Social identity complexity. Personality and Social Psychology Review, 6(2), 88-106. 
Rogoff, B. (2003). The cultural nature of human development. New York: Oxford University Press.

Rudmin, F. (2009). Constructs, measurements and models of acculturation and acculturative stress. International Journal of Intercultural Relations, 33(2), 106-123.

Sam, D. L., \& Berry, J. W. (2010). Acculturation when individuals and groups of different cultural backgrounds meet. Perspectives on Psychological Science, 5(4), 472-481.

Schachter, E. P. (2004). Identity configurations: A new perspective on identity formation in contemporary society. Journal of Personality, 72(1), 167-200.

Schachter, E. P. (2005). Context and identity formation: A theoretical analysis and a case study. Journal of Adolescent Research, 20(3), 375-395.

Schwartz, S. J., Zamboanga, B. L., Luyckx, K., Meca, A., \& Ritchie, R. A. (2013). Identity in emerging adulthood: Reviewing the field and looking forward. Emerging Adulthood, 1(2), 96-113.

Seidman, E., Allen, L., Aber, J. L., Mitchell, C., \& Feinman, J. (1994). The impact of school transitions in early adolescence on the self-system and perceived social context of poor urban youth. Child Development, 65(2), 507-522.

Serpell, R. (2007). Bridging between orthodox western higher educational practices and an African sociocultural context. Comparative Education, 43(1), 23-51.

Shepherd, D., \& Williams, T. (2016). Hitting rock bottom after job loss: Bouncing back to create a new positive work identity. Academy of Management Review. Manuscript published online ahead of print.

Shweder, R. A. (1999). Why cultural psychology?. Ethos, 27(1), 62-73. 
Suárez-Orozco, C., Abo-Zena, M. M., \& Marks, A. K. (2015). Transitions: The development of children of immigrants. New York University Press.

Syed, M. (2010). Developing an integrated self: Academic and ethnic identities among ethnically-diverse college students. Developmental Psychology, 46(6), 1590-1604.

Syed, M. (2012). The past, present, and future of Eriksonian identity research: Introduction to the Special Issue. Identity: An International Journal of Theory and Research, 12(1), $1-7$.

Syed, M., \& Azmitia, M. (2010). Narrative and ethnic identity exploration: A longitudinal account of emerging adults' ethnicity-related experiences. Developmental Psychology, 46(1), 208-219.

Syed, M., Azmitia, M., \& Cooper, C. R. (2011). Identity and academic success among underrepresented ethnic minorities: An interdisciplinary review and integration. Journal of Social Issues, 67(3), 442-468.

Syed, M., \& McLean, K. C. (2016). Understanding identity integration: Theoretical, methodological, and applied issues. Journal of Adolescence, 47, 109-118.

Syed, M., \& Mitchell, L. L. (2015). Temporal identity integration as a core developmental process. In R. Scott, \& S. Kosslyn (Eds.). Emerging Trends in the Social and Behavioral Sciences (pp. 1-15). San Francisco, CA: Wiley.

Szabo, A., Ward, C., \& Fletcher, G. J. (2016). Identity processing styles during cultural transition: Construct and measurement. Journal of Cross-Cultural Psychology, 47(4), 483-507. 
Tajfel, H., \& Turner, J. C. (1986). The social identity theory of intergroup behavior. In S. Worchel \& W. G. Austin (Eds.), Psychology of intergroup relations, (pp. 7-24). Chicago: Nelson-Hall.

Thorne, A., Cutting, L., \& Skaw, D. (1998). Young adults' relationship memories and the life story: Examples or essential landmarks? Narrative Inquiry, 8(2), 237-268.

van Hoof, A. (1999). The identity status field re-reviewed: An update of unresolved and neglected issues with a view on some alternative approaches. Developmental Review, 19(4), 497-556.

Verkuyten, M. (2016). Further conceptualizing ethnic and racial identity research: The social identity approach and its dynamic model. Child Development, 87(6), 17961812.

Yoon, E., Chang, C. T., Kim, S., Clawson, A., Cleary, S. E., Hansen, M., ... \& Gomes, A. M. (2013). A meta-analysis of acculturation/enculturation and mental health. Journal of Counseling Psychology, 60(1), 15.

Waterman, A. S. (1982). Identity development from adolescence to adulthood: An extension of theory and review of research. Developmental Psychology, 18, 341-358.

Waterman, A. S. (2015). Identity as internal processes: How the "I" comes to define the “Me.” In K. C. McLean \& M. Syed (Eds.), The Oxford handbook of identity development (pp. 195 - 209). Oxford, UK: Oxford University Press.

Waters, T. E., \& Fivush, R. (2015). Relations between narrative coherence, identity, and psychological well-being in emerging adulthood. Journal of Personality, 83(4), 441451. 
Way, N., \& Rogers, O. (2015). “[T]hey say Black men won’t make it, but I know I’m gonna make it": Ethnic and racial identity development in the context of cultural stereotypes. In K. C. McLean \& M. Syed (Eds.), The Oxford handbook of identity development (pp. 269 - 285). New York: Oxford University Press.

Wigfield, A., Eccles, J. S., Mac Iver, D., Reuman, D. A., \& Midgley, C. (1991). Transitions during early adolescence: Changes in children's domain-specific self-perceptions and general self-esteem across the transition to junior high school. Developmental Psychology, 27(4), 552-565. 


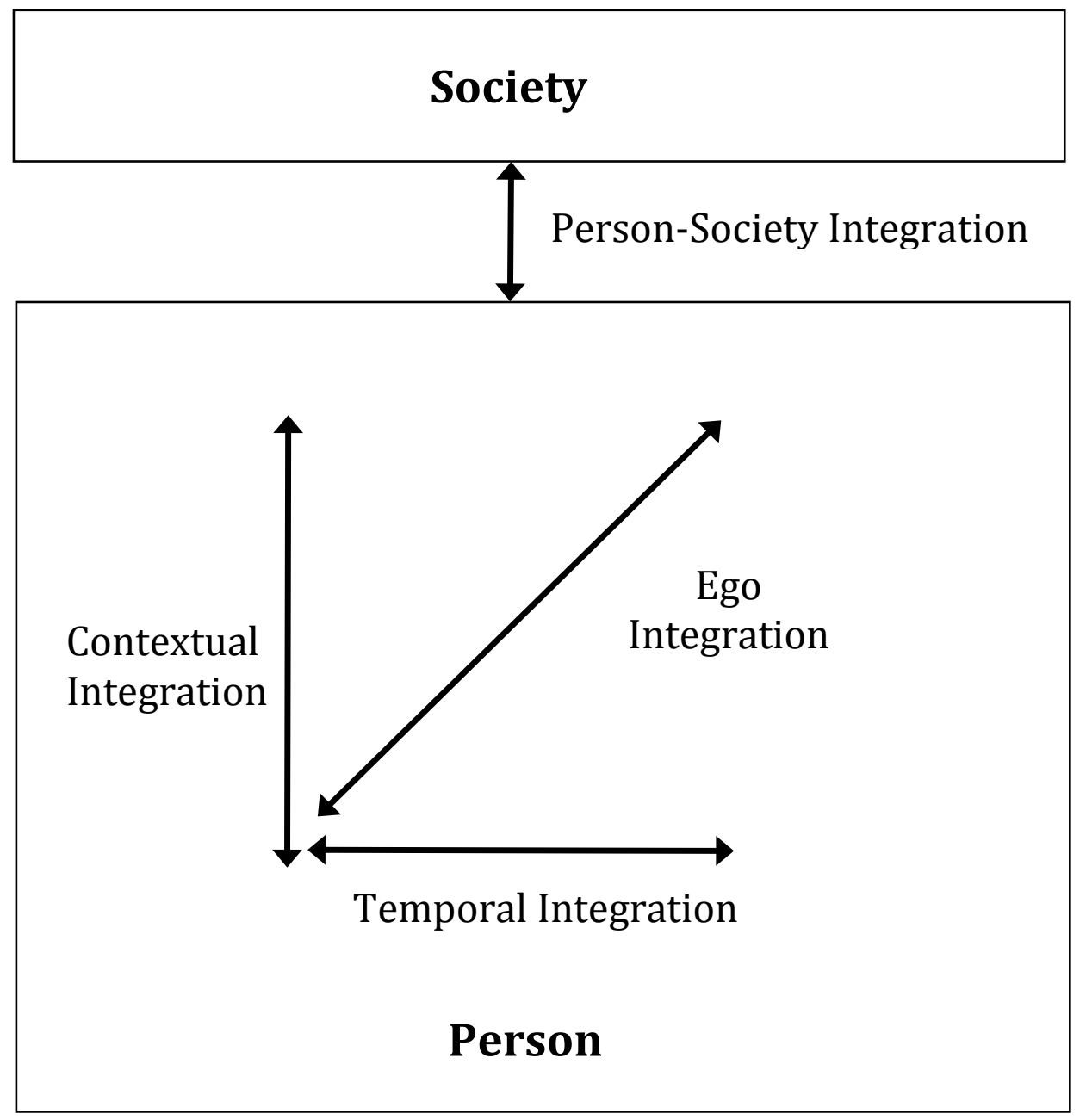

Figure 1. Schematic representation of four forms of identity integration. 